\title{
Strategies for School Environmental Management in Nigerian Secondary Schools: A Case of Calabar, Nigeria
}

\author{
Linus Beba Obong (corresponding author) \\ Department of Geography \& Regional Planning, University of Calabar, Nigeria \\ E-mail: linusobong@yahoo.com \\ Stella-Maris Okey \\ Educational Planning \& Administration \\ Cross River University of Technology, Calabar, Nigeria \\ E. J. Aniah \\ Department of Geography \& Regional Planning \\ University of Calabar, Nigeria \\ E-mail: geneaniah@yahoo.com \\ Lydia A. Okaba \\ Biology Department, Federal College of Education \\ Obudu, Cross River State, Nigeria \\ E-mail: de_lills@yahoo.com
}

\begin{abstract}
This paper on strategies for school environmental management in Nigerian secondary schools was carried out in Calabar, Nigeria. To guide the study three research questions were formulated. This was achieved through administration of structured questionnaires in three randomly sampled schools. Findings show regular grass clearing, sweeping of the school compound and painting, landscaping and planting of flowers, good drainage and refuse disposal are strategies adopted for managing the school environment. While lack of gardeners to keep the school compound clean, erosion, students and teachers not being responsive to environmental issues, difficulties to inculcate in students environmental values due to different home upbringing, lack of funds to procure working tools/implements and waste disposal challenges were some identified challenges in the school environmental management. Three hypotheses were put forward to be tested in the study: 1) There is no significant difference in strategies adopted in the management of school environment 2) Management of school environment has no significant effect on student study/reading habit 3) The challenges of managing school environment have no significant effect on the quality of school environment. Statistical results from tested hypotheses show significant relation and correlation in all. Result for hypothesis one shows that there is significant difference in strategies adopted in the management of school environment. Hypothesis two statistically proved that management of school environment has significant effect on students' study/reading habit; while the last stated hypothesis revealed that the challenges of managing school environment have significant effect on the quality of school environment. For enhanced and better school environment for sound academic exercise, school environmental management team (SEMT), fore-plan for drainage and waste disposal, school location consideration for new schools, employment of gardeners and cleaners, fumigation of schools, terminal orientation programmes, development of curriculum on environmental management, School inspection and competitions and awards were recommended.
\end{abstract}

Keywords: Strategies, School environmental management, Nigerian secondary schools, Nigeria

\section{Introduction}

The current challenge of environmental management is a general one. The quality of environment is crucial in creating a congenial and healthy environment for human welfare and productive life. Man manages his environment by getting rid of all wastes and by-products of different natural and anthropogenic processes introduced into the immediate environment. Environmental management has become one of the greatest challenges facing the world today. Managing the environment for fruitful, healthy and productive living is central to all human activities. 
Maintaining a sound and healthy environment has always been a challenge to man (Akintola, 1978). For example, the different inputs from anthropogenic activities include energy generating heat, uncontrolled sound turning into noise, and other land using agencies that causes spoliation of the physical environment. Various human activities that requires planning and coordination demands a comprehensive and deliberate effort to keep the physical environment fit for the total man to function well.

Hence, the management of built environment is determinant to the quality of man at any given time. Where this is undermined, there is bound to be poor physical conditions and the consequence is poor human output. Of particular interest is the school environment. The physical outlook of the school environment is very important in contributing to healthy academic exercise. It forms the fulcrum on which other activities revolve. This is because it creates an atmosphere of the mind for study. The challenge of developing and managing a school environment taking into consideration some parameters is a great one; one of such is the school location.

Where a school is located can determine to a large extent the stability of the student's mind for academic readiness. A school located along air-traffic route, roadside (especially without a fence), in neighbourhood of industrial activities, markets, and so on will constitute a nuisance and interference with the students' learning process. It will generate noise enough to badly affect the study adventure.

As indicated by the National Teachers' Institute (NTI, 2008; Mckay, 1964 in Egim, 2003) school supervision and sanitation. These are capable of affecting the quality of learning environment. This refers to all the strategies adopted by a school system in managing the wastes (noise, water, and other effluents), drainage pattern, and the facilities provided in the school. Equally crucial is the greening of the school environment. Sanitation Connection (2001/2002) maintains that a school management that provides sanitation and planting of flowers, trees and maintaining lawns, well cleared grasses, etc. improves quality of life and study environment.

Aesthetics of a school environment is another aspect of managing a school environment. Regular painting and maintaining the quality of buildings, channeling of sewage, well planned landscape and trimming of flowers, clearing of grasses, proper disposal of refuse, sweeping and removing cub webs among others provides a relaxed atmosphere for the molding of minds.

All these issues above constitute school environmental management strategies that could make a school a place to live and not to leave. In spite of this all-important top burner matter, very little have been done in managing school environments for fruitful academic venture. It becomes necessary to conduct a study on the strategies employed in managing school environment in Nigerian secondary schools.

How a school environment is managed in aesthetics, recreation, waste, drainage pattern, and other physical outlook of the environment has telling effect in the quality of learning environment of children.

This study was therefore designed to investigate the strategies for school environmental management in Nigerian secondary schools; envisioning that the study could provide and enhance the management of school environments in Calabar, Nigeria.

\section{Concept of environment}

Environment has been variously conceptualized to include all the natural resources of air, land and water; visible and invisible elements that affect the development of an organism for its lifetime. Environment refers to all the conditions and influences affecting the development of an organism in its lifetime. Man's total environment includes all the living and non-living elements in his surroundings which could be natural or built (man-made), etc. in a complex network of systems (Okaba and Obong, 2006; Edu, 2006). It also refers to all natural resources, joint property of man of which one man's right of use must not adversely affect the right of use of other joint owners (Offiong, 2003; Verla, 2003; Eni, 2005; Obong, 2007b). The current global awareness of the environment and its pivotal role to human endeavours and survival started mounting with the 1972 United Nation's World conference on Human Environment.

As identified by Obong (2007b), three major segments of environment include the natural, built and personal environments. The built and personal environments are what to a large extent determine the conditions of a school environment. The particular concern here is that it is the product of anthropogenic activities.

As posited by Eni (2005), human beings have characteristically lived in two worlds. The first is the natural world of nature consisting of plants, animals, soils, air and water that preceded the existence of man by hundreds of million years of which man is an integral and inescapable part. The second is the world of social institutions and artifacts (built world) that man deliberately creates for himself using science, technology, culture, political organization, and so forth.

As part of the deliberate world created by man is the school environment that constitute the learning atmosphere for the young minds. Neglecting to manage this environment is to undermine the future of any society.

\section{Concept of sustainability and sustainable development}

The early research in the area of sustainability is believed to have been championed by Danella and Daniel Meadows in the early 1970s. The Meadow's work involved the use of computer simulations, and predicted that within ten years the 
earth would begin to show great strain due to the earth's expanding population and continued development and was titled "Limits to Growth" (Murphy, 1998).

Several other works followed this publication such as the World Conservation Strategy (WCS), in collaboration with United Nations Environment Education Programme (UNEP), the World Wildlife Fund (WWF), the Food and Agriculture Organization of the United Nations (FAO) and the United Nations Educational, Scientific and Cultural Organization (UNESCO). It was prepared by the International Union for the Conservation of Nature and Natural Resources (IUCN) in 1980 (Hall and Lew, 1998). The published document was intended to informing governments about: (a) damaging environmental practices; (b) addressing the problem of overpopulation on a global scale, and (c) formulating a plan to tackle the unsustainable practices that were taking place at that time.

This report was instrumental to the United Nations' Stockholm Conference in 1972 and the Rio Summit in 1992 (Hall and Lew, 1998). In 1987, the United Nations' Commission on the Environment and Development (UNCED), after the World Conference on Human Environment chaired by the Norway's Prime Minister Mrs. Grow Harlem Bruntland came up with a report on the need for sustainable development. The conference defined sustainable development as development that "meets the needs of the present without compromising the ability of future generations to meet their own needs". It came up with five primary principles of sustainability including: (a) holistic planning, (b) preserving ecological processes, (c) protecting human heritage and biodiversity, (d) long-term sustainability of production, and (e) balancing equality between nations. The concept of environmental management is as old as man. It originated with God when He made man. According to the Holy Bible, "Then the LORD God took the man and put him in the Garden of Eden to tend and keep it" Genesis 2:15. The Garden is the environment, while to tend is to manage. Environmental management therefore is the process of keeping the earth in order through controlling, coordinating, planning and ensuring that the surrounding conditions of man are congenial and livable.

\section{Literature review}

The physical environment of a school adds a lot of value to the school (Obong, 2007a). Egim (2003) observed in her study on School Environment and Administrator's Role Performance in Cross River State Secondary Schools believes that the physical environment contributes either negatively or positively to the administrator's role performance in the school. The school physical environment includes the buildings, classrooms, furniture, equipment, instructional materials, laboratories, libraries, play grounds, and so on. Others are walls, machinery, decorative objects, play fields, skating rinks, swimming pools, audio-visual equipment (Mckay, 1964 in Egim, 2003). Egim (2003) maintained that in a bid to expand the educational enterprise, educational planners are more interested in issues such as the number of schools, teachers, students' infrastructural facilities like classrooms and school buildings. Little attention is paid to the quality of the environment.

The design and structure of school environment forms the physical appearance of the school which may attract parents and friends of educational institutions in their initial judgments about the quality of what goes on in the school. They have effect on the perception and choice for learning experience desired by parents and students (Mitchell, 2008). Available in the literature on strategies for school environmental management is rather scanty. A web work provides that school environment management plan (SEMP, 2008) should include the schools major environmental objectives; sub-committee recommendations for achieving these objectives through curriculum, school resources, and school grounds; audit results and plans specific for major objectives such as paper, resource use, energy, water; and review actions.

Learning environment has seen been emphasized as an essential requirement for smooth teaching and learning process to take place (National Teachers' Institute, NTI, 2008). This is because students' study habits are to a large extent tied to it. According to Sharon Mitchell, director of Mental Health, Wellness and Safety Promotion (2008), "the environment in which you study can have a big effect on how efficient your study time is". He identified noise, interruptions, lighting, temperature, neatness, comfort and equipment to have potential effect on study habits. This is supported by Sanitation Connection (2005) which posits that as schools provide an important learning environment, the promotion of personal hygiene and environmental sanitation within schools is essential. In addition schools provide ideal environment in which to help children to adopt good habits that will serve for the rest of their lives.

However, managing school environment has posed great challenges over the years to the government, principals and administrators. The challenges range from location, beautification, waste materials, landscaping, sanitation, greening, and so forth. These issues have occupied some studies by researchers such as Sanitation Connection (2002) and Egim (2003); Obong (2007a). It is common to see school environments poorly maintained. They are often strewn with litters of papers, dusty classrooms, poor ventilation, and landscaping for sit-outs during break periods. Such environments as agreed by Ikpaya (1987), deprives rather than stimulating learning and intellectual development. Little attention seems to be given to the quality of learning environment, perhaps because educational planners and administrators have not been adequately informed on the environment's role in enhancing learning and intellectual development. Interruptions 
from aircrafts, poor acoustics and spurious sounds have been identified as distractive to the learning process (Mackay, 1964 in Egim, 2003).

Further examined in the literature include library conditions for reading and writing which are often unwelcoming; toilets and urinary systems staring school management with irritating and mind-blighting stench; insect bites and so on (Banuri, et al,1994; Egim, 2003; Obong, 2007a).

\section{Statement of research problem}

The deplorable conditions of Nigerian school environments have become a serious worry in recent times. Children are often said to be future leaders. The place to lay a solid foundation, build and equip their lives to be better future leaders is the school environment. It is however, a concern that the school environments in which these young minds are trained have not been adequately managed. Even literature is very scanty or not there at all on this critical issue of school environmental management strategies.

Location of schools has not been a concern to the authorities running them. For instance, it is common to find schools located by commercial and other activities that generate noise such as automobiles, neighbourhood human discussions, discotheques, etc. to the extent that distract the concentration of learners.

Management of waste materials/substances is another problem. Solid waste materials like papers, cellophanes, pack from wrappings, tins, wood, etc littering the environment and class rooms. Where attempts are made to sweep, heaps of refuse are uncontrollably dumped haphazardly and jumbled up together unsorted with both degradable and non-degradable materials which mixes up and causing mind-blighting stench; harboring mosquitoes and pests such as rats, cockroaches, and eyesores.

The buildings on the other hand are another source of worry. Most school environments are not regularly painted. They are dilapidated and often in shambles which make schools dull and unattractive; this tantamount to creating a very hostile study environment not congenial to our children who must take their place as leaders of tomorrow with their counterparts in the developed world.

Aesthetics of most Nigerian schools are almost zero. Beautification of schools in creating lawns landscaping and planting of flowers with regular trimming; planting of shrubs for shade; clearing of grasses, etc are not thought of or of little concern.

The channeling of surface water through drains is another problem. During rains, it is common to see class rooms leaking; school environments flooded with run-off and making the children very uncomfortable. These are what this study fully explored in the school environment of Calabar, Nigeria.

\section{Research questions}

The study was guided by the following research questions:

1. What strategies are there in managing the school environment?

2. What relationship exists between school environment management and students' study habits?

3. What problems are there in the school environment?

4. Does the managing of school environment have an effect on the quality of school environment?

\section{Research hypotheses}

Tested in the study were the following hypotheses:

1. There is no significant difference in strategies adopted in the management of school environment

2. Management of school environment has no significant effect on student study/reading habit

3. The challenges of managing school environment have no significant effect on the quality of school environment.

\section{Significance of the study}

Planning is future oriented and embraces a comprehensive consideration of different aspects of a project, programme or scheme. This is normally done at the drawing board as a pre ante/prerequisite to the desired programme/project. At this level, anything that is not considered and included in the plan (master plan) at the end of the day may become difficult to integrate.

Over the years, however, the Nigerian secondary school environment have suffered neglect in consideration of issues of planning secondary schools. This is obvious in the way drainage patterns are designed, waste disposal systems/practices, sanitary location and general outlook of Nigeria secondary schools.

This study will be relevant in providing some strategies for planners, administrators, policy and decision makers with respect to education in creating a more healthy and productive learning environment. 
It will add to the body of literature on school environmental management strategies.

The work will equally awaken and create awareness on both the teachers and the students on the need for teaching and learning how to manage the environment.

\section{Methods}

This study adopts the survey and inferential method in investigating strategies for school environmental management in Nigerian secondary schools. The reason is because it uses representative sample from which findings were made with reference for the whole population. Three secondary schools were randomly sampled (West African Peoples' Institute (WAPI), Calabar; Holy Child Secondary School, Marian Hill Calabar; and Government Science School, Akim, Calabar) for on-the-spot assessment/observation and questionnaire administration.

A total of 100 senior secondary students - senior secondary one, two and three were randomly administered with copies of structured questionnaire; while a total of 30 questionnaires were administered to the teachers which were all properly filled and returned. Out of the 100 questionnaire administered to students, 2 were poorly filled hence discarded. Those properly filled and returned were what constitute the primary data for analysis. Respondents for this study made up of males and females. The simple random sampling technique was used to select 33 students each from the two selected schools and 34 for the other school. Descriptive statistics was used in describing the data gathered from the field at 0.05 level of significance. Data was presented in tables, charts, graphs and simple percentages. This was to make findings clearer and more understandable.

\section{Data presentation and Results}

Table 1 shows the various ways by which school environment is managed. A total responses of 38.8 per cent (a) said that the school environment is managed through regular grass clearing, sweeping of the school compound and painting, 23 respondents representing 23.5 (d) indicated others, 21.4 per cent. Others as indicated include lessons, orientation and debates. (c) have landscaping and planting of flowers, while 16.3 per cent (b) are of the view that good drainage and refuse disposal is the strategy in school environmental management.

As revealed in Table 2, figure 1 the management of school environment do not have any effect at all on the reading/study habit of about 20.4 per cent of respondents (c), 8.2 per cent says it has effect on their reading/study habit (a), 17 responses representing 17.3 per cent of respondents find managing school environment affecting their concentration in class during lessons (b), while 54.1 per cent represent others.

However, a total of 40.0 per cent of teachers from table 3 shows that students, school Gardeners and Cleaners are involved in school environmental management. 16.7 per cent of the respondents are of the view that students and gardeners alone are involved, 10.0 per cent shows that only school gardeners and cleaner play the role, while 20.0 per cent have a different opinion specifying that teachers, students, parent teachers, school gardeners and cleaners all play roles in managing the school environment.

As shown in Table 3, the challenges of managing school environment have serious effect on the quality on the school environment with 6.6 (a) per cent responses, while 46.7 per cent (b) are of the opinion that they do not have any serious effect on the school environment, 20 (c) per cent rather feels that the challenges have no effect at all on the quality of the school environment, and 26.7 (d) per cent indicated others.

As revealed in table 4 the prominent problem in the school environment to the students is noise from moving vehicles disturbing during lessons. This item has total responses of 26 persons making up 26.5 per cent. It is followed by sanitation problems/safe water supply with 21.4 per cent, littering with papers, wrappings, dust and uncollected refuse with 14.3 per cent and erosion/flooding with 13.3 per cent. Waste disposal had 11 responses with a percentage of 11.2 , snake bites, scorpion stings, and other insect bits had a response of 6.1 and others 7.1 per cent (Figure 2).

\section{Test of hypotheses}

\section{Hypothesis 1}

$\mathrm{H}_{\mathrm{o}}$ : There is no significant difference in strategies adopted in the management of school environment

$\mathrm{H}_{1}$ : There is significant difference in strategies adopted in the management of school environment

In testing this hypothesis Table 1 was used.

Degree of freedom $(\mathrm{df})=(2-1)(4-1) \quad=3$

Table value of $\mathrm{X}^{2}$ at 0.05 significant level $\quad=7.815$

$\mathrm{X}^{2}$ calculated $\quad=20.1$

Decision: From the statistical result in observation Table 5, the calculated $\mathrm{X}^{2}$ value of 20.1 was greater than the critical $\mathrm{X}^{2}$ value of 7.815 at 0.05 level of significance with 3 degrees of freedom. By this result, the null hypothesis $\left(\mathrm{H}_{\mathrm{o}}\right)$ is 
rejected and the alternate $\left(\mathrm{H}_{1}\right)$ which states that "There is significant difference in strategies adopted in the management of school environment", accepted.

\section{Hypothesis 2}

$\mathrm{H}_{\mathrm{o}}$ : Management of school environment has no significant effect on students'study/reading habit.

$\mathrm{H}_{1}$ : Management of school environment has significant effect on students' study/reading habit.

Tables $1(\mathrm{X})$ and $2(\mathrm{Y})$ were used to test the hypothesis.

Degree of freedom $\quad=2$

Table value of $t$ at 0.05 significant level

r calculated

Decision: From the statistical result, the calculated $t$ value of 4021 is greater than the tabulated/critical $t$ value of 4.303 at 0.05 level of significance with 2 degrees of freedom. By this result, the null hypothesis $\left(\mathrm{H}_{\mathrm{o}}\right)$ is rejected and the alternate $\left(\mathrm{H}_{1}\right)$ which states that "Management of school environment has significant effect on students' study/reading habit" accepted.

\section{Hypothesis 3}

$\mathrm{H}_{\mathrm{o}}$ : The challenges of managing school environment have no significant effect on the quality of school environment.

$\mathrm{H}_{1}$ : The challenges of managing school environment have significant effect on the quality of school environment. Table 4 was used to test this hypothesis.

Degree of freedom $(\mathrm{df})=(2-1)(5-1) \quad=4$

Table value of $\mathrm{X}^{2}$ at 0.05 significant level $\quad=9.488$

$\mathrm{X}^{2}$ calculated $\quad=9.93$

Decision: From the statistical result in observation Table 7, the calculated $X^{2}$ value of 9.93 was greater than the tabulated/critical $\mathrm{X}^{2}$ value of 9.488 at 0.05 level of significance with 4 degrees of freedom. By this result, the null hypothesis $\left(\mathrm{H}_{\mathrm{o}}\right)$ is rejected and the alternate $\left(\mathrm{H}_{1}\right)$ which states that "The challenges of managing school environment have significant effect on the quality of school environment", accepted.

\section{Discussion}

Generally, findings reveal regular grass clearing, sweeping of school compound and painting as major management strategies of school environment. Others include landscaping and planting of flowers, and good drainage and refuse disposal. Management of school environment was identified to have effect on the reading/study habit of some students, while to some it has no effect as tabulated in Table 2. It is obvious that it is not just a notion that when management of school environment is glossed over or neglected, it will eventually have adverse effect on the quality of school environment. It agrees with the findings of Ikpaya (1987) that such challenges deprive rather than stimulating learning and intellectual development. Concerted efforts must be put in place to check such challenges like noise from moving vehicles disturbing during lessons, sanitation problems/safe water supply, littering with papers, wrappings, dust and uncollected refuse, snake bites, scorpion stings, and other insect bits.

Answering the research question, "What problems are there in the school environment?", Table 4 and as depicted in Figure 2 revealed noise from moving vehicles disturbing during lessons. This item has total responses of 26 persons making up 26.5 per cent. It is followed by sanitation problems/safe water supply with 21.4 per cent, littering with papers, wrappings, dust and uncollected refuse with 14.3 per cent and erosion/flooding with 13.3 per cent. Waste disposal had 11 responses with a percentage of 11.2. Another problem noted in the school environment is snake bites, scorpion stings, and other insect bits with a total response of 6.1. Earlier studies such as Egim (2003) have shown that ensuring a sound school environment enhances the performance of even the administrator's role, let alone the students. These problems are capable of crippling the performance of all academic activities in general, hence, the need to address them.

Three hypotheses were stated to be tested and results shows significant relation and correlation in all (see Tables 5, 6, and 7). Statistical result for hypothesis one shows that calculated chi-square $\left(\mathrm{X}^{2}\right)$ value of 20.1 was greater than the critical chi-square $\left(\mathrm{X}^{2}\right)$ value of 7.815 at 0.05 level of significance with 3 degrees of freedom. The implication of this is that there is significant difference in strategies adopted in the management of school environment.

Whereas some schools adopt regular grass clearing, sweeping of school compound and painting, others use landscaping and planting of flowers, drainage and refuse disposal as well as teaching students to manage their environment.

Hypothesis two statistically proved that management of school environment has significant effect on students' study/reading habit. With 2 degrees of freedom at 0.05 level of significance, calculated t-value of 4021 was greater than 
the tabulated/critical t-value of 4.303. It therefore becomes important that management of school environment be a concern as it will enhance many students' study with consequence of performance.

Every stakeholder of education should contribute their quota in providing a comfortable study atmosphere of the students in Nigeria secondary schools. The last stated hypothesis revealed that the challenges of managing school environment have significant effect on the quality of school environment. It is obvious that it is not just a notion that when management of school environment is glossed over or neglected, it will eventually have adverse effect on the quality of school environment.

This was observed by Banuri et al (1994) that toilets and urinary are not given adequate attention in keeping with the health of students in the bid to develop their mental faculties. It agrees with the findings of Ikpaya (1987) that such challenges deprive rather than stimulating learning and intellectual development. Concerted efforts must be put in place to check such challenges like noise from moving vehicles disturbing during lessons, sanitation problems/safe water supply, littering with papers, wrappings, dust and uncollected refuse, snake bites, scorpion stings, and other insect bits had a response, and so on.

\section{Conclusion and recommendations}

From the findings of this study, the following conclusions were drawn: since a good and clean school environment enhances effective teaching and learning as well as promotes healthy living in the school, the need for proper management of the school environment cannot be over-emphasized. There is need for every available strategies and persons to be used in keeping the school environment clean and beautiful.

In the light of the above the following recommendations are put forward for better management of the school environment:

1. School environmental management team (SEMT): School management should constitute a team with a duty of managing school environment. Members of this team should include the Principal or his/her vice, representatives from the teachers, a student representation, representatives from the parent-teacher association (PTA), and the cleaners/gardeners. This team will keep surveillance while ensuring that school environmental problems are properly managed.

2. Fore-plan for drainage and waste disposal: Drainage considerations and how refuse, trash or waste materials will be evacuated from school environment. This can be effective and efficient when sitting a school is contemplated. It should be part of the plan right from start.

3. School location consideration for new schools: Location of schools should be given prime place. Places or location away from noisy neighbourhoods is more advisable. Disturbance from automobile noise and other unhealthy distractions affect students' concentration in studies.

4. Fumigation of schools: Use of pesticides and insecticides in treating offices and school environment will remove insect bites and infestation from insects and pests from the environment. When done it will provide for a safe study milieu.

5. Employment of gardeners and cleaners: Some schools do not have gardeners and cleaners. Students alone cannot effectively keep the school environment tidy. Government should employ these staff for the tidying of the school compounds.

6. Terminal orientation programmes: Schools should introduce orientation programmes at the beginning of every term. This will reorient the students' mindset for managing the study environment.

7. Development of curriculum on environmental management: A curriculum should be developed on school environmental management for Nigeria secondary schools and should be made compulsory.

8. School inspection: Inspection of various aspects of school environment should be made part of the seasonal school inspection and supervision. In both private and public schools.

9. Competitions and awards: Introduction of competitions and awards to best schools with best environmental practices in school environmental management should be encouraged. These will give a better school environment for a more fruitful academic endeavour; while teachers, gardeners and students should be encouraged to contribute their quotas to the management of school environment.

10. Development of uniform strategies for the management of school environment: The government should collaborate with schools and proprietors of private schools to develop uniform strategies in managing school environment.

\section{References}

Akintola, F. O. (1978). Aspects of Solid Waste Management in Ibadan City. Geographers and Planning in Nigeria, University of Jos.

Banuri, et al (1994). Sustainable Human Development from Concept to Operation: A Guide for the Practitioner. United Nations Development Programme New York. 
Curriculum Support Education (2008). "School Environment Management Plans". http://www.curriculumsupport.education.nsw.gov.au/policies/envired/emp/index.htm

Edu, N. (2006). Man in the Tropical Environment. Calabar: Unical Printing Press.

Egim, S. A. (2003). School Environment and Administrators' Role Performance in Cross River State Secondary Schools. An Unpublished Doctoral Thesis Submitted to the Department of Educational Administration and Planning, University of Calabar, Nigeria.

Eni, D. D. (2005). Philosophy and Methodology of Environmental Science. Calabar, Ultimate Index Book Publishers.

Ikpaya, B. O. (1987). Exceptional Children and Youths: An Introduction to Special Education. Calabar: Jameson Printing Special.

Mckay, R. L. (1964). "How to keep School Noise at the Right Level”. The Nation's Schools, 74(4), 64-67.

Mitchell, S. (2008). "Study Habits \& Test Anxiety". Mental Health, Wellness and Safety Promotion. Resources for Students. University at Buffalo. http://ub-counseling.buffalo.edu/stressstudy.shtml please correct.

Murphy, P. (1998). Tourism and Sustainable Development, in W. Theobald (Ed.), Global Tourism, (2 ${ }^{\text {nd }}$ ed.). Oxford, UK: Butterworth Heinemann.

National Teachers' Institute (NTI, 2008). "The Learning Environment” in Psychology of Education. Reading manual for Post Graduate Diploma in Education by Distance Learning Services.

Obong, L. B. (2007a). Waste Management Education: A Panacea For Effective Solid Waste Management. Journal of Scientific and Industrial Studies, 5(3), 69-73.

Obong, L. B. (2007b). Understanding the Environment: Concepts, Principles and Applications. Calabar: Penile Publishers.

Offiong, V. I. (2003). Environmental Law Enforcement Problem A Study of the Calabar Urban Development Authority (CUDA) Nigeria. An Unpublished M.Sc. Thesis Submitted to the Department of Geography and Regional Planning, University of Calabar, Calabar.

Okaba, L. A., \& Obong, L. B. (2006). Man and the Environment. Lagos: Horesgate Trust Ltd.

Sanitation Connection (2001/2002). Introduction to Solid Waste Management. www.sanicon.net

Sanitation Connection (2005). School Sanitation. Htpp://www.sanicon.net

The Holy Bible, New King James Version (1980). Thomas Nelson, Inc.

Verla, A. W. (2003). Man and His Environment: An Introduction to Environmental Science. Enugu: Jeef Robin Publishers.

Table 1. Strategies for management of school environment

\begin{tabular}{|l|l|l|}
\hline Strategies & Number of Respondents & Percentage (\%) \\
\hline a & 38 & 38.8 \\
\hline b & 16 & 16.3 \\
\hline c & 21 & 21.4 \\
\hline d & 23 & 23.5 \\
\hline
\end{tabular}

Source: Fieldwork, 2009.

a - regular grass clearing, sweeping of the school compound and painting

$\mathrm{b}-$ good drainage and refuse disposal

c - landscaping and planting of flowers

$\mathrm{d}-$ others

Table 2. Effect of school environmental management

\begin{tabular}{|l|l|}
\hline Strategies & Number of Respondents \\
\hline a & 8 \\
\hline b & 17 \\
\hline c & 20 \\
\hline d & 53 \\
\hline
\end{tabular}

Source: Fieldwork, 2009. 
a - it has effect on their reading/study habit

$\mathrm{b}$ - find managing school environment affecting their concentration in class during lessons

$\mathrm{c}$ - management of school environment do not have any effect at all on the reading/study habit

$\mathrm{d}$ - others

Table 3. Effect of the challenges of managing school environment

\begin{tabular}{|l|l|}
\hline Challenges & Number of Respondents \\
\hline $\mathrm{a}$ & 2 \\
\hline $\mathrm{b}$ & 14 \\
\hline $\mathrm{c}$ & 6 \\
\hline $\mathrm{d}$ & 8 \\
\hline
\end{tabular}

Source: Fieldwork, 2009

Table 4. Problems in school environment

\begin{tabular}{|l|l|l|}
\hline Problem & Number of respondents (\%) & Percentage (\%) \\
\hline Waste disposal & 11 & 11.2 \\
\hline Safe water supply & 21 & 21.4 \\
\hline Moving vehicles & 26 & 26.5 \\
\hline Erosion and flooding & 13 & 13.3 \\
\hline Insect bites, stings, etc & 6 & 6.1 \\
\hline Dust and uncollected refuse & 14 & 14.3 \\
\hline Others & 7 & 7.1 \\
\hline
\end{tabular}

Table 5. summary of observation Table 1

\begin{tabular}{llll}
\hline $\mathbf{X}^{2}$ Calculated & $\mathbf{X}^{2}$ Tabulated & Degree of freedom (df) & Confidence level \\
\hline 20.1 & 7.815 & 3 & 0.05 \\
\hline
\end{tabular}

Table 6. summary of observation Table for hypothesis 2

\begin{tabular}{|c|c|c|c|c|}
\hline $\mathbf{r}$ & T-calculated & T-tabulated & $\begin{array}{ll}\text { Degree } & \text { of } \\
\text { freedom (df) }\end{array}$ & Confidence level \\
\hline 2401 & 0 & 4.303 & 2 & 0.05 \\
\hline
\end{tabular}

Table 7. summary of observation Table for hypothesis 4

\begin{tabular}{llll}
\hline $\mathbf{X}^{\mathbf{2}}$ Calculated & $\mathbf{X}^{\mathbf{2}}$ Tabulated & Degree of freedom $(\mathbf{d f})$ & Confidence level \\
\hline 9.93 & 9.488 & 4 & 0.05 \\
\hline
\end{tabular}




\section{Effect of school environmental management}

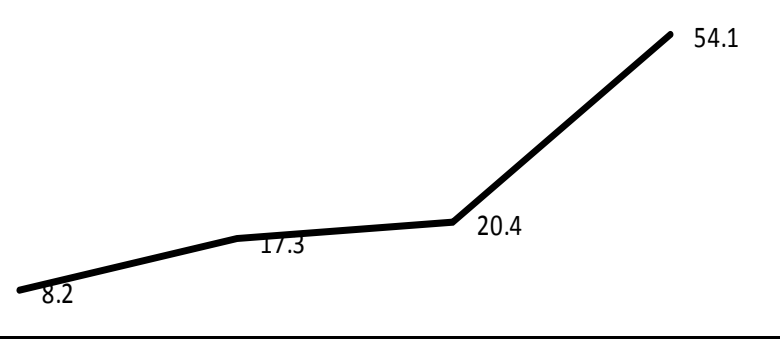

Has effect(a) Affectconcentration No effect(c)

Others (d) in class (b)

Figure 1. Showing effect of school environmental management

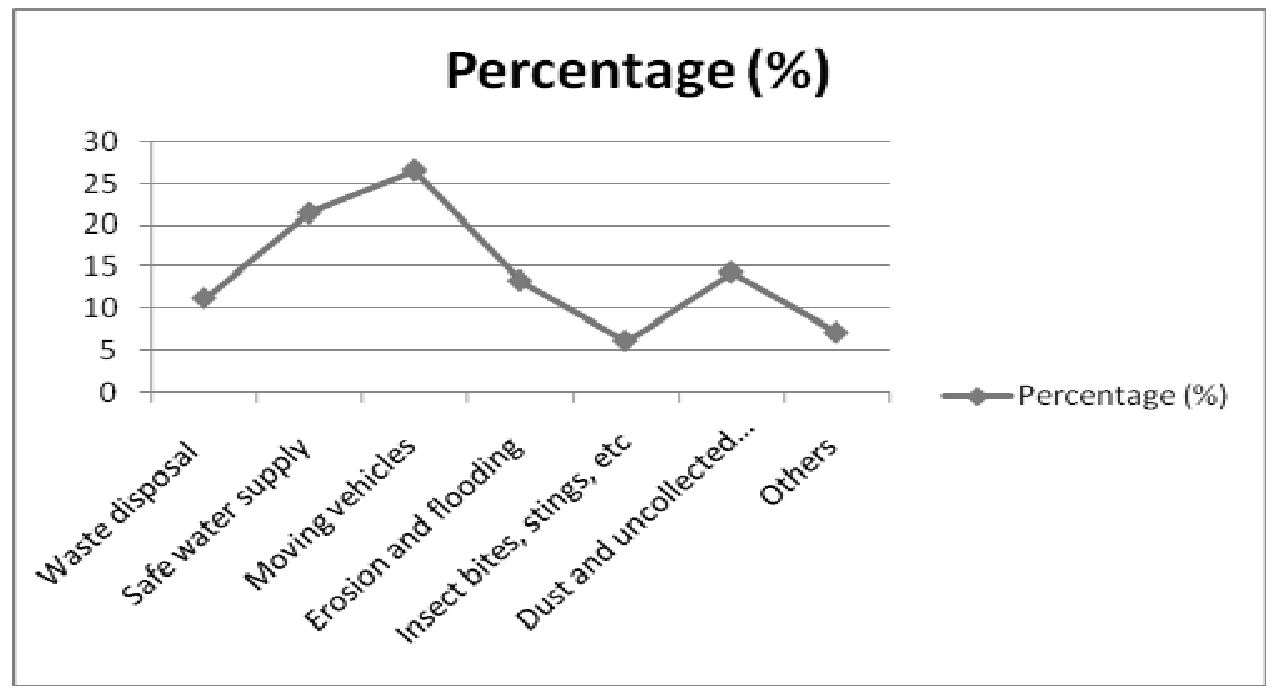

Figure 2. Prominent environmental problems in schools 